Method

\title{
Transforming chemical proteomics enrichment into high-throughput method using SP2E workflow.
}

Tobias Becker ${ }^{1}$, Andreas Wiest $^{1}$, András Telek ${ }^{1}$, Daniel Bejko ${ }^{1}$, Anja Hoffmann-Röder ${ }^{1}$, Pavel Kielkowski ${ }^{*}$

${ }^{1}$ LMU Munich, Department of Chemistry, Munich, Germany.

* Corresponding author. E-mail: pavel.kielkowski@cup.Imu.de.

Keywords Chemical proteomics, SP3, protein post-translational modifications, AMPylation, Glycosylation.

Subject Categories Methods \& Resources; Proteomics

\begin{abstract}
Protein post-translational modifications (PTMs) play a critical role in the regulation of protein catalytic activity, localization and protein-protein interactions. Attachment of PTMs onto proteins significantly diversifies their structure and function resulting in so-called proteoforms. However, the sole identification of post-translationally modified proteins, which are often cell type and disease specific, is still a highly challenging task. Sub-stoichiometric amounts and modification of low abundant proteins necessitate purification or enrichment of the modified proteins. Although the introduction of the mass spectrometry-based chemical proteomic strategies have enabled to screen protein PTMs with increased throughput, sample preparation has remained highly time consuming and tedious. Here, we report an optimized workflow for enrichment of PTM proteins in 96-well plate format which can be possible extended to robotic automatization. This platform allows to significantly lower the input of total protein, which opens up the opportunity to screen specialized and difficult to culture cell lines in high-throughput manner. The presented SP2E protocol is robust, time- and cost-effective as well as suitable for large-scale screening of proteoforms. Application of the SP2E protocol will thus enable the characterization of proteoforms in various processes such as neurodevelopment, neurodegeneration and cancer and may contribute to an overall acceleration of the recently launched Human Proteoform Project.
\end{abstract}




\section{Introduction}

Protein PTMs are crucial for regulation and fine-tuning of many important biological processes such as neurodevelopment (Becker et al, 2021; Mansfield \& Gordon-Weeks, 1991; Zheng et al, 2021; Aebersold et al, 2018), circadian-clocks (Brüning et al, 2019) or ageing (Truttmann et al, 2018) and impaired in numerous diseases (Rogowski et al, 2010; Hoch \& Polo, 2020; Kam et al, 2018). The incredible diversity of genetic polymorphism, RNA splice variants and PTMs results in many so-called proteoforms (Aebersold et al, 2018; Smith et al, 2019, 2021), which exceed the $\sim 20,000$ human genes by approximately fifty times. This biological network orchestrates the most complex processes including the brain development and ensures a dynamic response of the cells to an external stimulus. However, the extent of protein PTMs in laboratory-cultured cells can differ significantly depending on cell types, diseases and culture conditions. Mass spectrometry (MS)-based chemical proteomics has allowed to reliably map protein PTMs across various experimental conditions (Laughlin \& Bertozzi, 2007; Kallemeijn et al, 2021; Martin et al, 2011; Parker \& Pratt, 2020; Kielkowski et al, 2020a, 2020b). A widespread application of the chemical proteomic strategy was enabled by parallel improvements of liquid chromatography technologies, gains in speed and sensitivity of mass spectrometers and bioinformatic pipelines for protein identification and quantification (Sinha \& Mann, 2020; Cox \& Mann, 2008; Tyanova et al, 2016; Yu et al, 2020). Nowadays, chemical proteomics is used to uncover the scope of protein PTMs in different cell types by the development of small molecule probes which mimic their natural counterparts. The utilization of these probes has provided valuable insights into protein acetylation, palmitoylation, myristylation, prenylation, glycosylation, ADP-ribosylation and AMPylation (Grammel et al, 2011; Becker et al, 2021; Kliza et al, 2021; Laughlin \& Bertozzi, 2007; Martin et al, 2011; Kallemeijn et al, 2021; Yang et al, 2010; Sieber et al, 2020). In general, different chemical proteomic workflows follow the same sequence of the key steps (Fig 1A). First, cultured cells are treated with the probe which infiltrates the cellular system and competes with the endogenous substrate for the active site of the PTM writer enzymes. Next, the chemical proteomic probes usually contain an alkyne or azide handle to facilitate a bioorthogonal coupling to suitable biotin linkers with either Cu-catalyzed alkyne-azide cycloaddition (CuAAC) or copper free strain-promoted azide-alkyne cycloaddition (SPAAC), respectively (Parker \& Pratt, 2020; Agard et al, 2004). Following the click chemistry, proteins are precipitated from to remove the excess of biotin reagents and non-protein components of the cell lysate (Kallemeijn et al, 2021; Becker et al, 2021). In the next step, biotin-labelled proteins are enriched using avidin-coated beads. The critical part of this step is to maximize the efficiency of the washing to remove nonspecifically bound proteins and thus to reduce the complexity of the final MS sample. After reduction and alkylation of the enriched modified proteins, they are digested by 
bioRxiv preprint doi: https://doi.org/10.1101/2022.01.24.477214; this version posted January 25, 2022. The copyright holder for this preprint (which was not certified by peer review) is the author/funder, who has granted bioRxiv a license to display the preprint in perpetuity. It is made available under aCC-BY-NC 4.0 International license.

trypsin or another protease, desalted and concentrated for MS measurement. The measurement time can be lowered by multiplication using plethora of isotopically labelled MS tags such as tandem mass tag (TMT)(Zecha et al, 2019). Alternatively, each sample is measured separately for the label free quantification (LFQ) providing the possibility to add more samples into dataset later on (Cox et al, 2014). MS data are typically acquired on orbitrap or timsTOF-based LC-MS/MS instruments. Finally, peptide and protein identifications and quantifications are carried out using well established commercial or free of charge pipelines such as MaxQuant or MSFragger (Yu et al, 2020; Cox et al, 2014). Comparison of the probe treated and control cells allows to distinguish unspecific protein binders and probe modified proteins. Despite the success of the chemical proteomic technology, the community of scientists combining organic synthesis, mass spectrometry and biology is still rather small. With numerous validated commercial PTM probes and the widespread availability of mass spectrometers either used in individual groups or as a core services, the bottlenecks of the chemical proteomic approach still remain in the insufficient consistency, time inefficiency and laboriousness of the enrichment techniques. Furthermore, the emerging field of chemical proteomic studies focused on neuronal differentiation and the complex environment of the central nervous system composed of many different cell types, is not compatible with the high amounts of total proteins that have been so far required for the analysis. In a perfect scenario, the workflow would be efficient even with a low protein input protein and the enrichment would require a minimum hands-on time or fully automatization. In comparison to standard MS whole proteome sample preparation methods, which include filter-assisted sample preparation (FASP), stage tips, iST, and single-pot solid-phase amplified sample preparation (SP3), the chemical proteomic method not only requires highly efficient protein and peptide purification, but also needs to be combined with suitable bioorthogonal reaction conditions and much higher starting protein amounts (Wiśniewski et al, 2009; Müller et al, 2020; Hughes et al, 2019; Sielaff et al, 2017). Thus far, the most common chemical proteomic methods for protein PTM enrichment utilize acetone or chloroform-methanol precipitation to remove the excess of click chemistry reagents (Kallemeijn et al, 2021). Further, enrichment with avidin-coated agarose beads requires centrifugation or filtration to separate them from the wash buffer. Of note, the Tate group combined avidin-coated magnetic beads and a trifunctional linker with azide, biotin and rhodamine to visualize the enriched proteins by in-gel analysis (Wright et al, 2014; Kallemeijn et al, 2021) and recently the Backus group has implemented the SP3 peptide cleanup into their chemical proteomic workflow before transferring the peptides including the biotinmodified peptides on avidin-coated agarose beads (Yan et al, 2021). Although similar affinity enrichment techniques combined with MS have been reported, to our best knowledge the procedure feasibly integrating all aspects of small-scale chemical proteomics is not available (Klont et al, 2021; Makowski et al, 2018). 
Here, we report the development and optimization of the chemical proteomic method which uses carboxylate-modified magnetic beads to clean-up the proteins after CuAAC and streptavidin-coated magnetic beads for the enrichment of the labelled proteins (Fig 1B). The new method termed SP2E was further scaled down to 96-well plate format, starting with 100 $\mu \mathrm{g}$ total protein. The SP2E method has been successfully used for profiling of protein glycosylation and the low abundant protein PTM called AMPylation. Together, the SP2E method provides a time-effective and robust platform for routine and high-throughput profiling of protein PTMs.

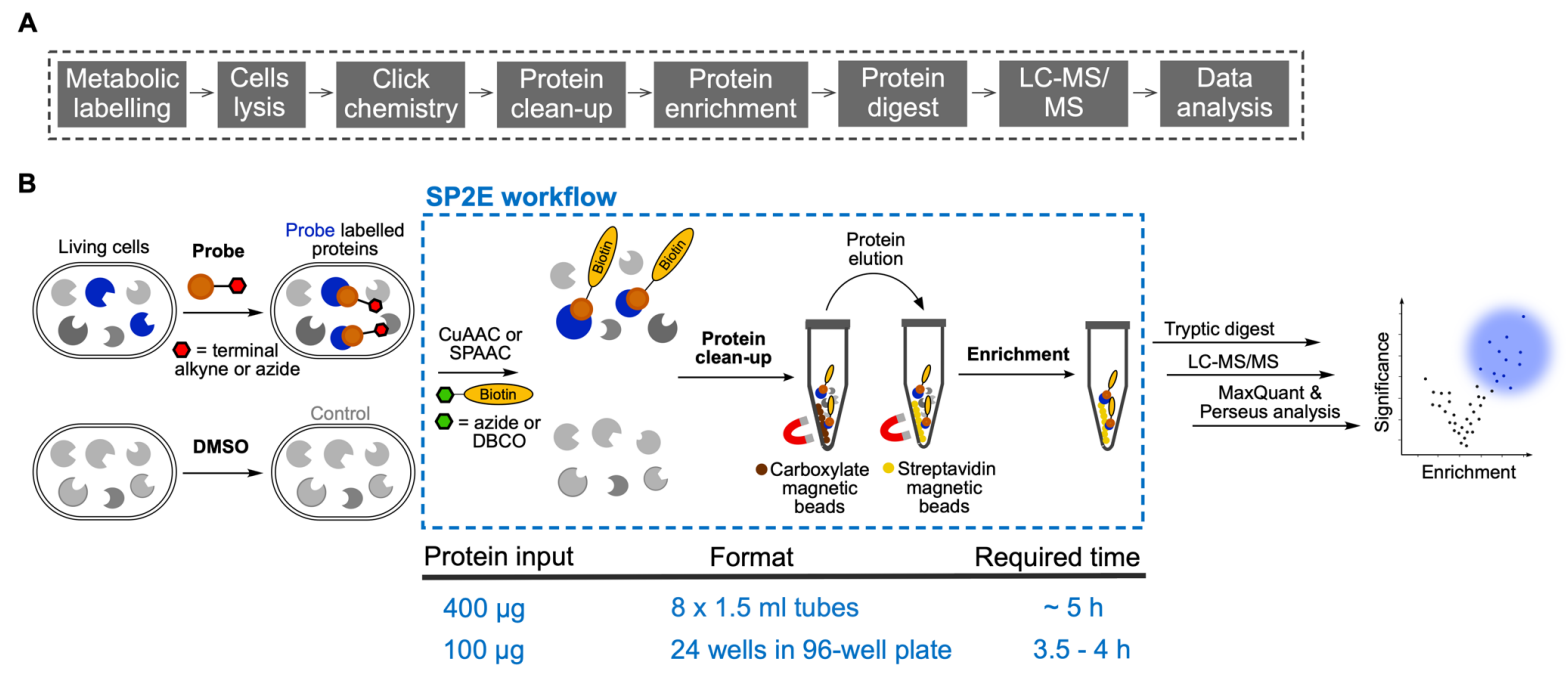

Figure 1. Schematic overview chemical proteomic workflow.

A Standard chemical proteomic workflow key steps.

B Schematic characterization of the SP2E workflow and basic parameters of the procedure.

\section{Results}

\section{Development of the SP2E workflow for chemical proteomics}

First, we set to optimize the lysis buffer composition to maximize the efficiency of the click chemistry. To evaluate this, the HeLa cells were treated with the pro-N6pA probe infiltrating protein AMPylation (Becker et al, 2021; Kielkowski et al, 2020b), harvested and lysed in nine different lysis buffers (Fig 2A). The CuAAC click chemistry was performed with $400 \mu \mathrm{g}$ total protein per sample and azide-TAMRA to visualize the conversion efficiency by in-gel fluorescence scanning after sodium dodecyl-sulfate polyacrylamide gel (SDS-PAGE) electrophoresis. The overall brightest fluorescence was observed in the lysis buffer containing $0.1 \%$ NP-40, $0.2 \%$ SDS in $20 \mathrm{mM}$ Hepes pH 7.5 (Fig 2B), which was used for all following experiments. Next, we focused on optimization of protein enrichment and mass sample preparation. To assess the enrichment efficiency, we decided to use a group of six known AMPylated maker proteins (HSPA5, CTSB, PFKP, PPME1, ACP2, ABHD6). In the first attempt $400 \mu \mathrm{g}$ total protein in $200 \mu \mathrm{L}$ lysis buffer was used for click chemistry with the azide-PEG ${ }_{3}-$ 
biotin. The resulting reaction mixture was transferred onto carboxylate-coated magnetic beads and followed by the addition of absolute $\mathrm{EtOH}$ to a final concentration of $60 \%$. After washing the beads three times with $80 \% \mathrm{EtOH}$, the streptavidin-coated magnetic beads were added directly to the carboxylate-coated magnetic beads and incubated for $1 \mathrm{~h}$ in $0.2 \%$ SDS in PBS to form the biotin-streptavidin complex. To remove the unmodified proteins, the beads mixture was washed thrice with $0.1 \%$ NP-40 in PBS, twice with $6 \mathrm{M}$ urea in water and thrice with LCMS grade water. The enriched proteins were subsequently reduced, alkylated and trypsin digested in ammonium bicarbonate $(A B C)$ buffer. The resulting peptides were eluted from the beads by two washes with the ABC buffer before desalting on off-line Sep-Pak C18 columns and separation on a UHPLC using a 150 min gradient with the high fidelity asymmetric waveform ion mobility spectrometry (FAIMS) device attached on the Orbitrap Eclipse Tribrid mass spectrometer. The MS data were analyzed by MaxQuant and evaluated in Perseus (Fig 2C)(Cox et al, 2014; Tyanova et al, 2016).

A

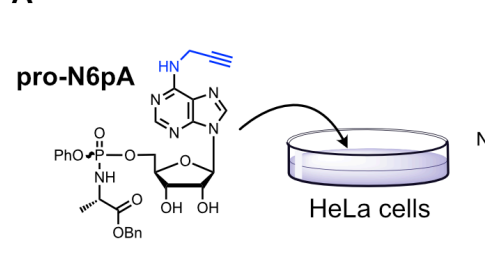

\section{c}

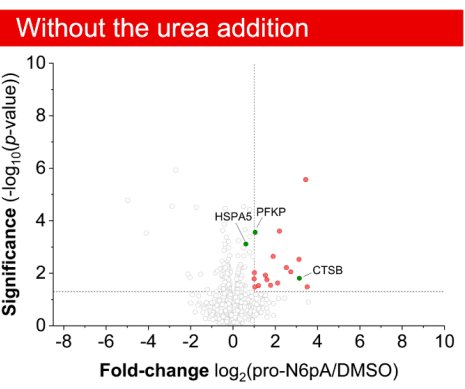

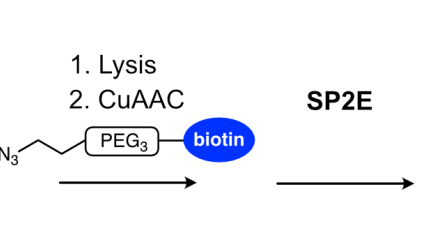

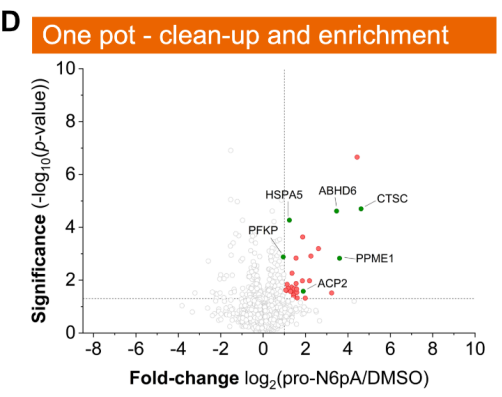

B

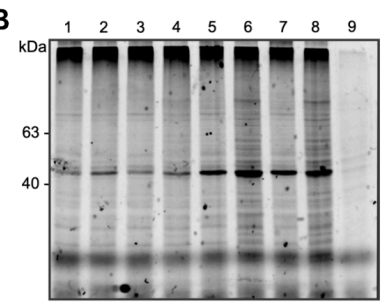

E

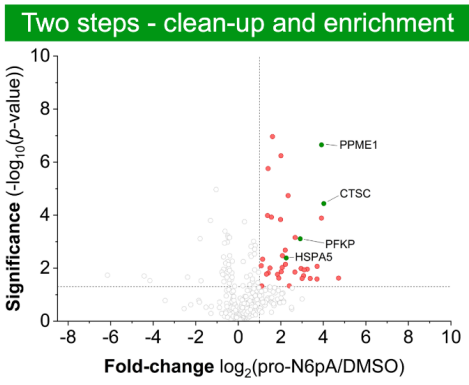

Figure 2. Development and optimization of the SP2E workflow using AMPylation probe.

A Pro-N6pA probe structure and workflow used for the optimisation of the SP2E method.

B Optimization of the lysis buffer based on the efficiency of the CuAAC click chemistry. Lysis buffer compositions: line 1 (1\% NP-40 in PBS), line 2 (1\% NP-40, 0.2\% SDS in PBS), line 3 (0.5\% Triton in PBS), line 4 (0.5\% Triton, 0.2\% SDS in PBS), line 5 (1\% NP-40 in 20mM Hepes), line 6 (1\% NP-40, 0.2\% SDS in 20mM Hepes), line 7 (0.5\% Triton in 20mM Hepes), line $8(0.5 \%$ Triton, $0.2 \%$ SDS in $20 \mathrm{mM}$ Hepes $)$, line $9(8 \mathrm{M}$ urea in $0.1 \mathrm{M}$ Tris $/ \mathrm{HCl})$.

C Volcano plot showing significantly enriched proteins (red dots) using the pro-N6pA AMPylation probe with highlighted marker proteins (green dots). The proteins were loaded onto carboxylate magnetic beads in the lysis buffer and enrichment was done in one pot combining carboxylate and streptavidin magnetic beads together. 
D The proteins after click reaction were loaded in lysis buffer supplemented with 4M urea. The enrichment was done in one pot together with carboxylate magnetic beads.

E Compared to the protocol used for Fig. 2C, the proteins were eluted after the protein cleanup on carboxylate coated magnetic beads and were transferred into a new $1.5 \mathrm{~mL}$ tube for enrichment containing streptavidin magnetic beads.

All volcano plots; $n=4$, cut-off lines at $p$-value $>0.05$ and 2 -fold enrichment.

We have observed that protein loading in lysis buffer directly after the click reaction onto carboxylate magnetic beads did not give satisfactory results with poor enrichment of the marker proteins (Fig 2C). Therefore, based on our previous experiments, we have tested whether the addition of concentrated urea to the click reaction mixture in lysis buffer may improve the protein clean-up. Indeed, the dilution of the lysis buffer to a final concentration of $4 \mathrm{M}$ urea has significantly improved the overall enrichment ratio (Fig 2D).

In the second step, we asked, whether it is possible to reduce the overall background by eluting the proteins from the carboxylate magnetic beads before adding them to the streptavidin-coated magnetic beads in a new tube, and thus improve the enrichment ratio. Therefore, directly after the clean-up on carboxylate magnetic beads, the proteins were eluted twice with $0.2 \%$ SDS in PBS and transferred onto streptavidin magnetic beads. The resulting volcano plot has confirmed that separate elution and transfer of the proteins are beneficial for their enrichment and hence outcompetes the advantage of performing both steps in one-pot (Fig 2E). In particular, the enrichment of HSPA5 and PFKP has increased by more than 2-fold.

Third, the digest and peptide elution conditions have been optimized. In principle, the possibility to combine the click chemistry with reduction and alkylation prior to protein cleanup on carboxylate beads, as described by Hughes et al. (Hughes et al, 2019, 2014), could improve the final elution and purity of the peptides. However, experimental testing of this possibility showed very poor enrichment of modified proteins, while standard reduction and alkylation with tris(2-carboxyethyl)phosphine (TCEP) and chloroacetamide (CAA) at $95{ }^{\circ} \mathrm{C}$ for 5 min directly before trypsin addition gave satisfying results (Fig 2E).

Taken together, we have optimized several steps of the SP2E protocol. First, we showed that the lysis buffer containing $0.1 \%$ NP-40, 0.2\% SDS in $20 \mathrm{mM}$ Hepes $\mathrm{pH} 7.5$ efficiently lyse the cells and improve the yield of the CuAAC. Furthermore, the addition of urea into the lysis buffer after click chemistry enhances protein binding to the carboxylate magnetic beads. Next, we demonstrated that it is possible to reduce the background by eluting the proteins from the carboxylated magnetic beads before adding them to the streptavidin magnetic beads. Finally, it was confirmed that the reduction and alkylation after the proteins' enrichment and prior to trypsination worked better in comparison to reduction and alkylation performed before the protein clean-up. 


\section{Application of the SP2E workflow for analysis of protein AMPylation}

To validate our approach a heterogeneous set of samples, we went on to screen metabolic pathways which may impact on protein AMPylation. In our previous studies, we showed that changes in protein AMPylation are linked to neurodevelopment of the human induced pluripotent stem cells (hiPSCs) (Becker et al, 2021; Kielkowski et al, 2020b). In particular, we have observed that a large group of lysosomal proteins is modified with the pro-N6pA probe and thus likely AMPylated. Most recently, we have described the intriguing changes in proteoforms of the 5'-3' exonuclease PLD3 (PLD3), which leads to accumulation of the soluble modified PLD3 in mature neurons. In line with our marker proteins used for the SP2E workflow development, we have consistently enriched a group of proteins localized to cytosol and mitochondria such as PFKP, PPME1, SLC25A3 and cytoskeletal proteins. Therefore, our and other reports has led to a controversy in the field, as the two thus far known AMPylators, FICD and SELENOO, are strictly localized to the endoplasmic reticulum (ER) and mitochondria, respectively (Truttmann et al, 2018, 2017; Sanyal et al, 2019). Now, with our optimized SP2E protocol in hand, we decided to determine the signaling pathways in which AMPylation may play a role. We have proceeded with a screening of five different inhibitors in SH-SY5Y neuroblastoma cells: rapamycin, bafilomycin, 2-deoxy-D-glucose, thenoyltrifluoroacetone (TTFA) and monensin. These inhibitors regulate mTOR, autophagy, glycolysis, cellular respiration and ER to Golgi sorting, respectively (Raught et al, 2001; Leeman et al, 2018; Yoshimori et al, 1991; Zhang \& Fariss, 2002; Mollenhauer et al, 1990). SH-SY5Y cells were treated either with the inhibitor alone or with the inhibitor and pro-N6pA probe to avoid any influence of protein expression changes triggered by addition of the inhibitor (Fig $3 A$ ). Additionally, two more controls were included. Cells treated with plain DMSO or only pro-N6pA probe to ensure the consistency with the previous results and to check the efficiency of the enrichment (Fig 3B). For each condition, four replicates have been prepared and the enrichment protocol has been started with $400 \mu \mathrm{g}$ total protein (Fig 3A). The resulting MS samples were analysed using a LC-MS/MS 150 min gradient and the peptides were identified and quantified by the LFQ method in MaxQuant. This has resulted in overall 100 significantly enriched proteins. The principal component analysis (PCA) showed a clear difference between control and probe treated samples and, interestingly, the samples that were treated with bafilomycin and monensin clustered together suggesting the robustness and feasibility of the SP2E workflow to discover new pathways involved in regulation of AMPylation (Fig 3C and Fig S1 and S2). Pearson correlation coefficients of MS intensities between the replicates has been over 95\% (Fig 3D). Of note, the analysis of the enriched proteins revealed the amyloid-beta precursor protein (APP) to be one of the most significantly enriched protein in cells treated with bafilomycin and monensin. 

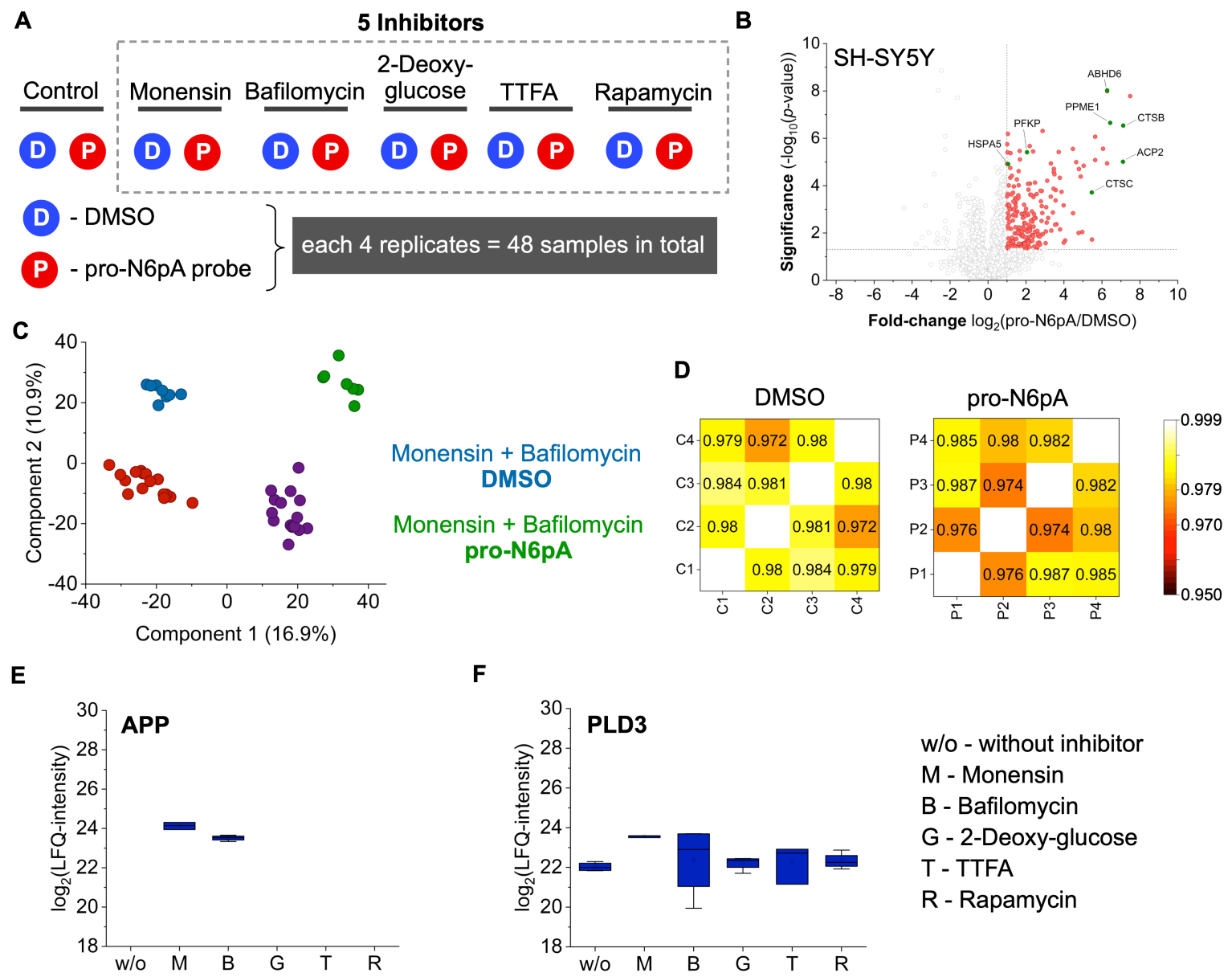

$$
\begin{aligned}
& \text { w/o - without inhibitor } \\
& \text { M - Monensin } \\
& \text { B - Bafilomycin } \\
& \text { G - 2-Deoxy-glucose } \\
& \text { T - TTFA } \\
& \text { R - Rapamycin }
\end{aligned}
$$

Figure 3. Analysis of protein AMPylation under different stress conditions using the SP2E workflow.

A Design of the experiment to test the impact of various inhibitors on protein AMPylation.

$B$ Volcano plot showing the enrichment of AMPylated proteins (pro-N6pA vs. DMSO) from SH-SY5Y cells using the SP2E protocol; $n=4$, cut-off lines at $p$-value $>0.05$ and 2 -fold enrichment.

C PCA of the inhibitors treated cells and controls display separation of the monensin and bafilomycin as well as pro-N6pA treated cells.

D Representative heatmaps visualizing the Pearson correlation coefficients of LFQ intensities of DMSO and pro-N6pA replicates.

E Profile plot displays the APP LFQ intensities under various conditions. The APP was not found in any other conditions, for example in cells only treated with DMSO or inhibitor.

F Profile plot displays the PLD3 LFQ intensities under various conditions.

Next, examination of the profile plots without imputed values showed that APP is only enriched in the cells that were treated with the pro-N6pA probe and either bafilomycin or monensin (Fig 3E). Interestingly, PLD3 has shown a strong response to the two inhibitors (Fig 3F). Subsequent search for similar enrichment profiles has uncovered a group of 12 proteins 
including GPR56, FAT1, LAMA4, TGOLN2, RNF149, CRIM1, ITM2B, L1CAM, TMEM59, MCAM, LRP1 and CLU that were specifically enriched under these two conditions. This would point towards the link between AMPylation and trafficking pathways from ER to lysosomes and autophagy.

To investigate the relationship between the monensin concentration and the AMPylation extent in more detail, SH-SY5Y cells were treated with increasing concentration of monensin in cell culture media ranging from $2 \mathrm{nM}$ to $2 \mu \mathrm{M}$ (Fig 4A). The concentration of the pro-N6pA probe was kept constant and each condition has been performed in duplicate. Surprisingly, the modification of PLD3 has risen by several folds even with the lowest inhibitor concentration and then it was steadily increasing with the monensin concentration (Fig 4B). In contrast, the modified APP was only found in cells treated with $1 \mu \mathrm{M}$ and $2 \mu \mathrm{M}$ monensin (Fig 4C). Indeed, PTMs of the amyloid-beta precursor protein are deemed to play an important role in development of the Alzheimer's diseases pathophysiology(Long \& Holtzman, 2019). By application of our SP2E workflow we showed that AMPylation might be an additional PTM involved in the regulation of the APP physiological function. Together, the screening of the AMPylation changes triggered by five different active compounds manifest the utility of the SP2E workflow, which is characterised by minimal background binding, its robustness and replicability.

A

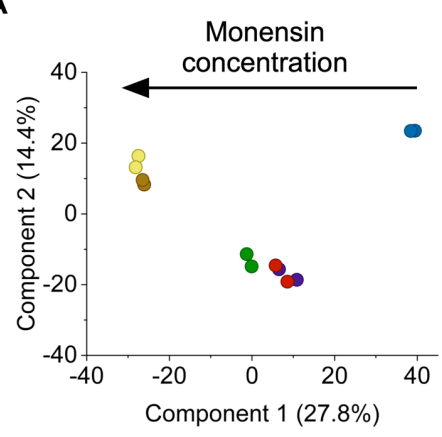

B

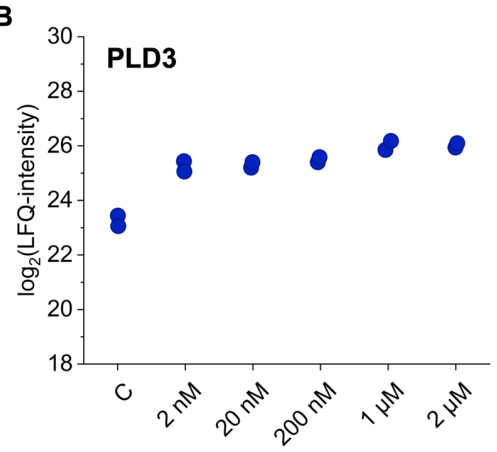

C

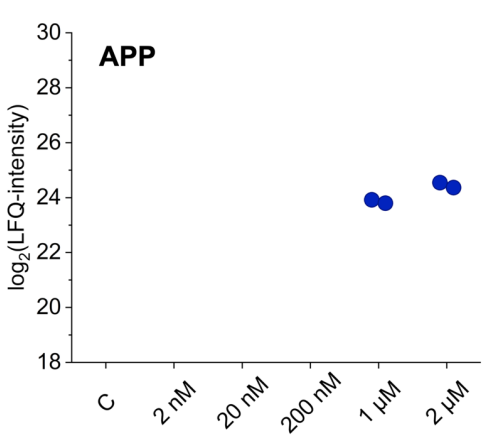

Figure 4. Monensin concentration dependent increase in APP and PLD3 modification.

A PCA displays distinct changes in the enriched proteins with increasing monensin concentration.

B Profile plot of the PLD3 LFQ intensities shows rapid increase of the PLD3 modification with $2 \mathrm{nM}$ monensin concentration.

C In contrast to PLD3, the profile plot of the APP LFQ intensity reveals that APP is only enriched with the pro-N6pA probe with $1 \mu \mathrm{M}$ and $2 \mu \mathrm{M}$ monensin in cell culture media. 


\section{Application of the SP2E workflow for analysis of protein O-GIcNAcylation}

To assess the utility of our optimized workflow for other PTMs, we used the previously described $\mathrm{Ac}_{3} 4 \mathrm{dGlcNAz}$ probe (GlcNAz) for the pull-down of $O$-linked $\beta$-N-acetyl-glucosamine glycosylated (O-GlcNAcylation) proteins (Fig 5A)(Yang \& Qian, 2017; Laughlin \& Bertozzi, 2007; Li et al, 2016; Pedowitz \& Pratt, 2021). Numerous metabolic labels have been developed for characterisation of O-GlcNAcylated proteins ( $\mathrm{Li}$ et al, 2016). However, they often suffer from low substrate specificity and labelling efficiency. Here, we used the 2,4-dideoxy-Dglucopyranose derivative, which shows improved specificity for cytosolic proteins (Li et al, 2016). In contrast to previous experiments with the pro-N6pA probe, the GlcNAz probe contains an azide functional group for bioorthogonal protein labelling using SPAAC (Fig $5 A)$ (Agard et al, 2004). To avoid unspecific reactivity of free thiols with the DBCO-biotin reagent utilized for the SPAAC, they were capped with iodoacetamide (Pentelute et al, 2018). Afterwards, the lysate proteins containing GICNAz were reacted with the DBCO-biotin reagent and enriched using the SP2E method in the same fashion as described above for AMPylation (Fig 5B). Interestingly, the high number of significantly enriched proteins leads to a clear separation of the probe treated and control samples in the PCA plot, with one component over $72 \%$ (Fig 5C). Furthermore, the SP2E enrichment of the O-GlcNAcylated proteins had a strong impact on the number of imputed values, as a high number of proteins were consistently identified only in the probe treated samples (Fig 5D). To our contentment, $95 \%$ of the 358 significantly enriched proteins were previously described as O-GlcNAcylated (www.oglcnac.mcw.edu), with one of the most significant hits being the well-studied cotranslationally O-GIcNAcylated protein NUP62 (Fig 5B-E, Fig S3)(Wulff-Fuentes et al, 2021). Together, these experiments demonstrate the utility of the SP2E protocol for the enrichment of metabolically labelled proteins.

A
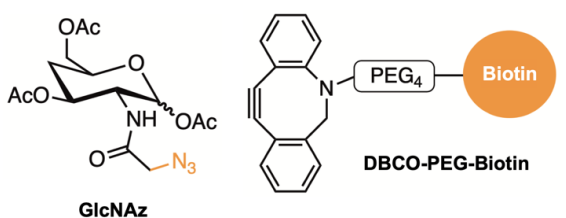

GICNAz

D

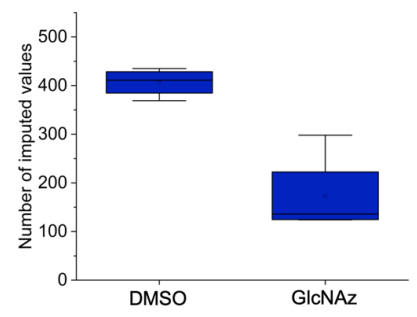

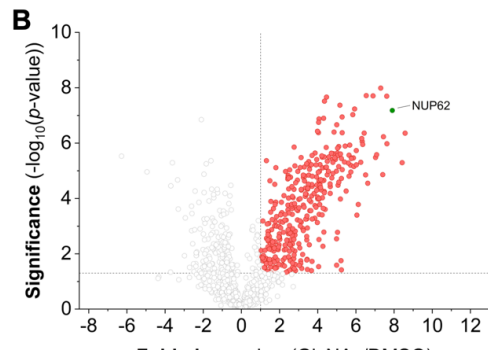

E

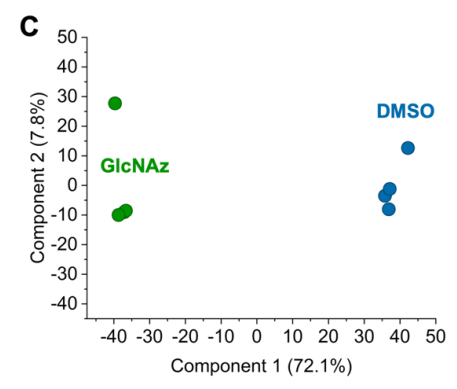

Component 1 (72.1\%)

Figure 5. Analysis of O-GIcNAcylation by GICNAz probe, SPAAC and SP2E workflow. 
A Chemical structure of GlcNAz probe for metabolic labelling of O-GlcNAcylated proteins and DBCO-biotin reagent to functionalize the probe modified proteins by SPAAC.

B Volcano plot visualizing the enrichment of the O-GlcNAcylted proteins; $n=4$, cut-off lines at $p$-value $>0.05$ and 2-fold enrichment. Red dots are significantly enriched proteins.

C PCA graph points to a clear separation of the control and probe treated samples. Of note, the component 2 possess a high value of $72.1 \%$.

D Comparison of the number of imputed values in DMSO and GIcNAz treated cells to demonstrate the clear difference between the two samples and enrichment efficiency.

E Diagram showing overlap between all significantly enriched proteins using GlcNAz probe and previously described O-GlcNAz proteins.

\section{Scale-down of the SP2E workflow into 96-well plate format}

Although, the combination of the carboxylate and streptavidin magnetic beads using SP2E streamlined the PTM protein enrichment, it remained to be demonstrated whether this approach is efficient with a lower protein inputs. Therefore, we have performed the enrichment starting with $100 \mu \mathrm{g}$ of total protein using lysates from pro-N6pA treated HeLa cells in a standard $1.5 \mathrm{~mL}$ eppendorf tube. Already in this first attempt, it was possible to significantly enrich 5 out of 6 AMPylation marker proteins (Fig 6A). Encouraged by the general feasibility of the SP2E workflow with lower protein input, we have moved on to scale down the protocol into 96-well plate format. The dynamic range of the SP2E enrichment efficiency has been shown on the enrichment of rather low abundant AMPylated proteins from pro-N6pA treated HeLa cells in 96-well plate format (Fig 6B). The initial testing with simple decrease of the click reaction volume to $20 \mu \mathrm{L}$ and wash steps to $150 \mu \mathrm{L}$ showed only poor enrichment results (Fig S4). Thus, we have adjusted the protocol with the following steps. The clean-up of the proteins after the click reaction was extended with an additional acetonitrile washing step, as used for the automated whole proteome samples preparation by Müller et al. (Müller et al, 2020). In addition, the reduction and alkylation step were omitted, proteins were digested in $50 \mu \mathrm{L}$ of TEAB and peptides were eluted from the streptavidin magnetic beads with $20 \mu \mathrm{L}$ TEAB and $20 \mu \mathrm{L} 0.5 \%$ formic acid (FA) buffer with an incubation at $40{ }^{\circ} \mathrm{C}$ for $5 \mathrm{~min}$ (Fig S4). The resulting MS samples have been acidified by addition of FA and the peptide mixture was resolved using a 60 min LC-MS/MS measurement (Fig 6B). In particular, usage of the shorter gradient is beneficial for two practical reasons. First, more samples can be measured in shorter time and second, the MS spectra files are smaller with overall less MS data to process, leading to a faster identification and quantification by search engines. Furthermore, the total amounts of enriched peptides are estimated to be still very low, the shorter gradient is likely resulting in more intense MS spectra and thus in more identified peptides (Fig 6B). Importantly, the Pearson correlation coefficients of the protein intensities remained still over $95 \%$ (Fig 6C). 
The efficiency of the optimised protocol in a 96-well plate has been further tested with the GlcNAz probe (Fig 6D). Indeed, it was possible to significantly enrich 174 proteins with NUP62 amongst the most significantly enriched ones (Fig 6D). Moreover, both TEAB and ABC buffers used for the digest provided comparable results. In order to elute the peptides efficiently from the streptavidin magnetic beads after digest, it is necessary to repeat the elution twice, although it results in peptides dilution in the final MS sample (Fig S4). Similar to the large-scale experiment, the SP2E procedure in the 96-well plate format displays an excellent separation in the PCA of the control and probe treated samples after enrichment (Fig 6E). In summary, our protocol promises to provide a fast, robust and high-throughput chemical proteomic platform, which may be used by biologists to assess the PTM status from a wide variety of cells. This is an important prerequisite to unravel the complex PTM networks and elucidating the underlying functional consequences of protein PTMs.

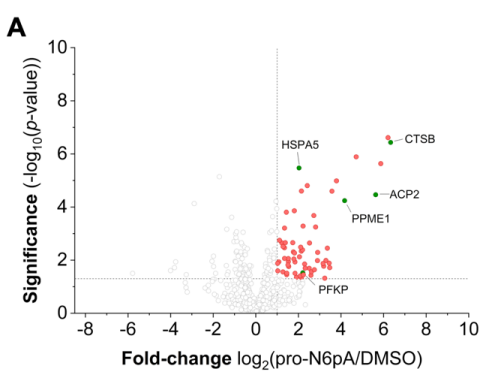

C

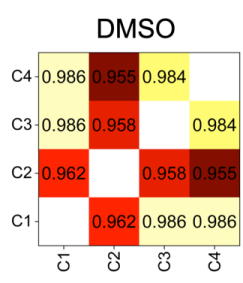

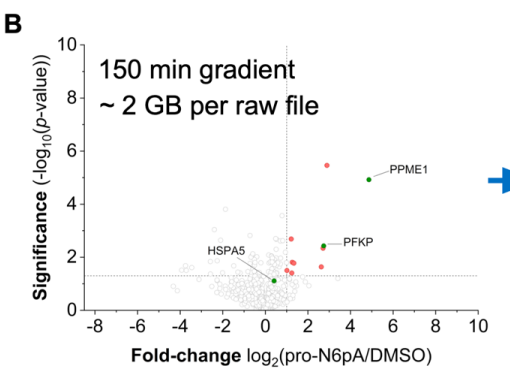

D

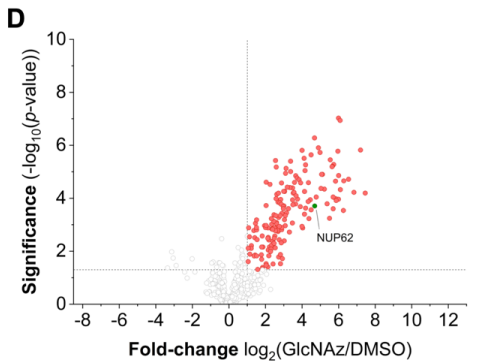

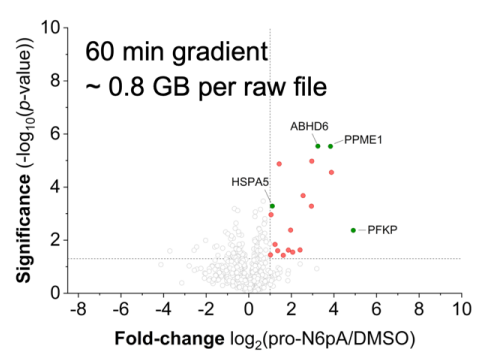

E

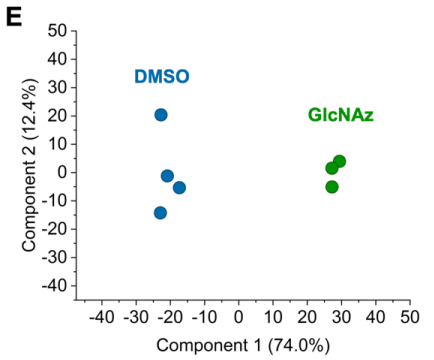

Figure 6. Scale-down of the SP2E workflow into 96-well plate format.

A SP2E protocol with $100 \mu \mathrm{g}$ input protein performed in $1.5 \mathrm{~mL}$ tubes visualized in the volcano plot.

B Optimization of the LC-MS/MS measurement with $100 \mu \mathrm{g}$ protein input using the 96 -well plate format SP2E protocol.

C Heatmaps representing the Pearson correlation coefficients between the replicates.

D Volcano plot showing the enrichment of O-GlcNAcylated proteins starting from $100 \mu \mathrm{g}$ input protein in 96-well plate format.

E PCA of the small scale GlcNAz enrichment shows a slightly better separation of controls from probe treated samples compared to large-scale SP2E in Fig 5B.

All volcano plots, $n=4$, cut-off lines at $p$-value $>0.05$ and 2 -fold enrichment. Red dots are significantly enriched proteins. 


\section{Discussion}

Chemical proteomics has enabled the characterization of many protein PTMs, which are otherwise inaccessible using the whole proteome analysis. Several enrichment workflows have been developed to make the procedure universal and feasible. However, the protocols often require to be carried out by specialized laboratory personnel, they are tedious and time consuming. Additionally, with increasing demand to screen protein PTMs in specialized cell types which are difficult to culture or not accessible in larger amounts typically required by the chemical proteomic protocols, it is of the paramount importance to streamline the enrichment workflow and to provide a platform which could be automatized. This would parallel the development of the high-throughput automatized whole proteome MS analysis. The transformation of the MS field has been underlined by the rapid improvement of speed and sensitivity of nowadays mass spectrometers. The progress of the MS instrumentation has been complemented by software tools allowing for fast and reliable protein identification and quantification. Together, these developments have created the suitable environment for transition of the chemical proteomic analysis of protein PTMs from the specialized field to become a more widely applied analytical tool.

Here, we describe the development and application of the SP2E workflow which enables the chemical proteomic characterization of protein PTMs in a small-scale, robust and time effective manner. The main difference to the previous MS-based chemical proteomic protocols is the utilization of the paramagnetic beads for both protein clean-up and enrichment. It leads to a better separation of solid and liquid phase and thus improved the removal of nonspecifically binding proteins during the enrichment steps. Furthermore, it allows a better separation as well in smaller volumes and it can be readily automatized. The initial substitution of the standardly used avidin-coated agarose beads with streptavidin-coated magnetic beads resulted in only moderate enrichment of the AMPylated marker proteins. Therefore, we have systematically evaluated each step of the enrichment protocol with focus on scale-down of the whole procedure. Starting with the lysis buffer, which is critical to ensure an efficient lysis already in a small volume to provide protein concentrations of up to $10 \mu \mathrm{g} / \mu \mathrm{L}$ and efficient click chemistry (Fig 2A). To complete the optimization of the Cu-catalyzed click reaction time, a time dependent experiment was carried out to show that the $1.5 \mathrm{~h}$ is necessary to maximize the yield of the reaction (Fig 7A). Next, enrichment efficiency was improved by separation of protein clean-up and enrichment which possibly allow efficient washing and, hence, less unspecific protein binding. The optimized protocol has been tested in large-scale experiments starting with 400 total protein to explore metabolic pathways in which protein AMPylation plays a role. In total, 48 samples have been prepared using five different inhibitors and four replicates 
per condition. The same pro-N6pA probe was utilized as for the optimisation of the workflow with the exception of SH-SY5Y neuroblastoma cells instead of the HeLa cells were used. Pearson correlation coefficient of protein intensities among all samples showed high correlation (> 0.95), demonstrating the robustness of the workflow. Interestingly, the PCA revealed a difference between the control and probe treated cells and importantly displays a clear change in enriched proteins from monensin and bafilomycin treated cells suggesting the specific role of AMPylation in cell stress response to these inhibitors. Moreover, this indicates the high efficiency of the wash steps during enrichment and reproducibility of the SP2E workflow. Concentration dependent analysis of monensin on pro-N6pA labelling showed that already two replicates of each condition provide sufficient information due to the high reproducibility of the procedure and revealed that the PLD3 modification rapidly increases with $2 \mathrm{nM}$ monensin concentration. This was then confirmed in the follow up in-gel analysis of the PLD3 using a trifunctional linker containing an azide, biotin and rhodamine. After SP2E based enrichment, proteins are released from the streptavidin magnetic beads by denaturation and separation on SDS-PAGE. Then, enrichment efficiency is assessed by in-gel fluorescence. Enrichment of PLD3 was additionally confirmed by western blot and, for the first time, uncover for the first time that only the soluble form of PLD3 is modified by the pro-N6pA probe and that there is a strong increase in the modified form upon addition of monensin (Fig 7B). Even though, the soluble and soluble-modified PLD3 are not even visible on the western blot of the whole lysate and the increase in modified PLD3 after enrichment is obvious (Fig 7C, D). Together, this demonstrates the efficiency of the SP2E enrichment.

To show the versatility of the procedure, we have performed the enrichment of $O$ GlcNAcylated proteins using the azido GIcNAz probe. The SPAAC click reaction followed by the SP2E workflow provided excellent enrichment of the well described glycosylated protein NUP62 with nominal values of 240 -fold enrichment and a $p$-value of $1 \mathrm{E}-7$. Furthermore, another 342 known glycosylated proteins were significantly enriched (95.5\%). The outstanding enrichment efficiency is visible by the number of missing values in the control samples (Fig 5D). Since protein glycosylation plays an important role in numerous metabolic processes and often serves as disease marker, our SP2E protocol offers the possibility to screen for the OGlcNAcylation in a high-throughput manner. This might not only accelerate the progress in the field, but also help to decipher the complex glycan patterns by application of different glycosylation labels.

Finally, current availability of chemical proteomic data shared in public repositories together with feasibility of sophisticated data analyses necessitate generation of high-quality data in a high-throughput manner. This can be only achieved by automatization of the procedures as for example with the autoSP3 protocol and other proteomic approaches. Here, we have scaled-down the SP2E workflow into the 96-well plate format, which retains the 
principle operations paralleled in autoSP3. Importantly, we showed on analysis of protein AMPylation and O-GlcNAcylation that $100 \mu \mathrm{g}$ input protein is sufficient for successful PTM protein profiling. This results in the same high correlations between the samples (in average $>0.96$ ) and achieves high fold-enrichments (NUP62 26-fold and HSPA5 2-fold). Although there is a drop in the overall number of enriched proteins, to $48 \%$ for AMPylation and $47 \%$ for $O$ GlcNAcylation, this is outweighed by cost and time efficiency due to smaller scale of cell culture, washing steps, usage of the multichannel pipettes, shorter measurement times and data processing. Of note, in case of AMPylation, $66 \%$ marker proteins were successfully enriched and for O-GlcNAcylation 173 proteins out of 174 significantly enriched proteins were previously described O-GlcNAcylated. To further shorten the time of the workflow, we have analysed the time-dependency of the biotin-streptavidin complex formation to find out that already $15 \mathrm{~min}$ is sufficient (Fig 7E, F respectively). Overall, the manual SP2E workflow with 24 samples in 96-well format can be carried out in 3.5 - 4 hours starting from the preparation of the click reaction to the addition of trypsin. After overnight trypsin digest, the peptides are eluted and transferred into MS-vials within additional 45 min.

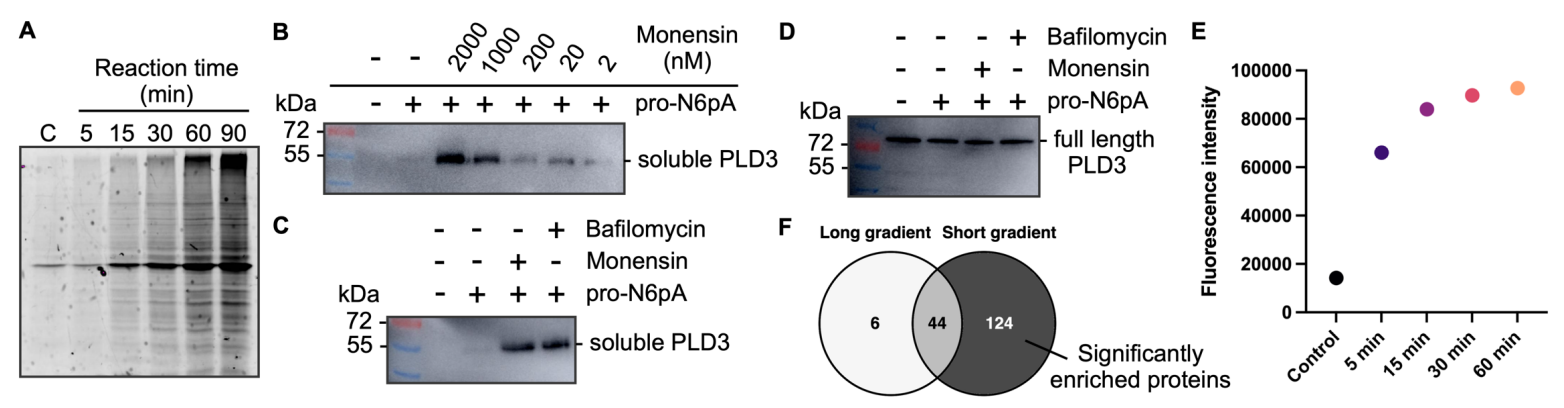

Figure 7. SP2E time-efficiency optimization and in-gel analysis of the PLD3 modification.

A In-gel fluorescence showing the click reaction time optimization. In the control (C), cells were treated with plain DMSO and the lysate was incubated with the click reaction mixture for $90 \mathrm{~min}$

B Enrichment of the modified PLD3 using the trifunctional linker (azide-biotin-rhodamine) in dependency on monensin concentration in cell culture media. PLD3 detected on the PVDF membrane using the anti-PLD3 antibody.

C Enrichment of the modified PLD3 using the trifunctional linker (azide-biotin-rhodamine) after the treatment with bafilomycin (100 nM) and monensin $(2 \mu \mathrm{M})$.

D Western blot of the whole proteome from cells treated with bafilomycin and monensin stained with anti-PLD3 antibody.

E Plot display total fluorescence intensity from the in-gel analysis of time optimization of biotinstreptavidin complex formation (see original gel in Fig S5). 
F Venn diagram comparing the number of significantly enriched proteins found after 96-well plate format SP2E of GlcNAcylated proteins using short (60 min) or long (150 min) LCgradient.

The limitation of the SP2E workflow for chemical proteomic characterisation of protein PTMs is the inherent necessity to treat the cells with small molecule probes, which are not always commercially available and thus need to be synthesized. Furthermore, the labelling ratio is often determined by the metabolic activation of probes and the substrate selectivity of PTM writers. Thus, it might be difficult to estimate the exact stoichiometry of protein modification. Similar to other proteomic approaches, the statistical evaluation includes the imputation of missing values and therefore it might be challenging to identify the hit proteins with low protein intensities as significantly enriched. However, some of these bottlenecks can be overcome by increasing the number of replicates.

In summary, the robust, time and cost-effective workflow we have developed will allow a wide range of scientist to characterise protein PTMs in the future, which might accelerate the deconvolution of the function of low abundant protein PTMs in diseases.

\section{Materials and Methods}

\section{Reagents and Tools Table}

\begin{tabular}{|l|l|l|}
\hline Reagent/Resource & Reference or Source & $\begin{array}{l}\text { Identifier or Catalog } \\
\text { Number }\end{array}$ \\
\hline Experimental Models & & \\
\hline Human: SH-SY5Y & Biedler et al., 1973 & RRID: CVCL_0019 \\
\hline Human: HeLa & Puck and Marcus, 1955 & RRID: CVCL_0030 \\
\hline Recombinant DNA & & \\
\hline I & & \\
\hline Antibodies & & $\begin{array}{l}\text { Cat\# HPA012800; } \\
\text { RRID: AB_1855330 }\end{array}$ \\
\hline Rabbit polyclonal anti-PLD3 & Sigma-Aldrich & $\begin{array}{l}\text { Cat\# A6667; RRID: } \\
\text { AB_258307 }\end{array}$ \\
\hline $\begin{array}{l}\text { Goat polyclonal anti-rabbit } \\
\text { lgG, HRP-linked }\end{array}$ & Sigma-Aldrich & \\
\hline $\begin{array}{l}\text { Oligonucleotides and other } \\
\text { sequence-based reagents }\end{array}$ & & Cat\# A955-212 \\
\hline / & & Cat\# G8541 \\
\hline $\begin{array}{l}\text { Chemicals, Enzymes and } \\
\text { other reagents }\end{array}$ & & \\
\hline Acetonitrile (LC-MS grade) & Thermo Fisher Scientific & Sigma-Aldrich \\
\hline Alanyl-Glutamine & & \\
\hline
\end{tabular}




\begin{tabular}{|c|c|c|}
\hline $\begin{array}{l}\text { Ammoniumperoxodisulfat } \\
\text { (APS) }\end{array}$ & Sigma-Aldrich & Cat\# 09913 \\
\hline Biotin- $-\mathrm{PEG}_{3}-\mathrm{N}_{3}$ & Carbosynth & Cat\# FA34890 \\
\hline BSA & AppliChem & Cat\# A6588 \\
\hline Coomassie Blue R-250 & Fluka & Cat\# 27816 \\
\hline $\mathrm{CuSO}_{4} \times 5 \mathrm{H}_{2} \mathrm{O}$ & Acros & Cat\# 10627162 \\
\hline ddH2O (LC-MS grade) & Honeywell & Cat\# 15665350 \\
\hline DMSO & Sigma-Aldrich & Cat\# D4540 \\
\hline Formic Acid (LC-MS grade) & Thermo Fisher Scientific & Cat\# A117 \\
\hline Hepes & Carl Roth & Cat\# HN77.5 \\
\hline NP40 & Sigma-Aldrich & Cat\# 74385 \\
\hline Methanol (LC-MS grade) & Thermo Fisher Scientific & Cat\# A456 \\
\hline Powdered milk & AppliChem & Cat\# A0830 \\
\hline SDS & AppliChem & Cat\# A2572 \\
\hline TAMRA-N $_{3}$ & Baseclick & Cat\# BCFA-008-1 \\
\hline TBTA & $\mathrm{TCl}$ & Cat\# T2993 \\
\hline TCEP & Carbosynth & Cat\# FT01756 \\
\hline TEAB (1 M) & Sigma-Aldrich & Cat\# T7408 \\
\hline TEMED & Sigma-Aldrich & Cat\# T9281 \\
\hline Tris-base & Thermo Fisher Scientific & Cat\# 10724344 \\
\hline Trypan Blue & Thermo Fisher Scientific & Cat\# 11538886 \\
\hline Urea & AppliChem & Cat\# A1049 \\
\hline DPBS $(1 \mathrm{x})$ & Sigma-Aldrich & Cat\# D8357 \\
\hline $\operatorname{DMEM}(1 \mathrm{x})$ & Sigma-Aldrich & Cat\# D6546 \\
\hline $\begin{array}{l}\text { Immobilon® Western HRP } \\
\text { Sustrate }\end{array}$ & Merck Millipore & Cat\# WBKLS0500 \\
\hline $\begin{array}{l}\text { Color Prestained Protein } \\
\text { Standard, Broad Range (10- } \\
250 \mathrm{kDa})\end{array}$ & New England BioLabs & Cat\# P7719S \\
\hline Rotiphorese.Gel $30(37,5: 1)$ & Carl Roth & Cat\# 3029.1 \\
\hline TrypLE Express & Thermo Fisher Scientific & Cat\# 12604013 \\
\hline Trypsin & Promega & Cat\# V5113 \\
\hline $\begin{array}{l}\text { Ammonium bicarbonate } \\
\text { (ABC) }\end{array}$ & Fluka & Cat\# 09830-100g \\
\hline Streptavidin magnetic beads & New England BioLabs & Cat\# S1420S \\
\hline $\begin{array}{l}\text { Carboxylate-coated magnetic } \\
\text { beads (hydrophobic) }\end{array}$ & Cytiva & $\begin{array}{l}\text { Cat\# } \\
65152105050250\end{array}$ \\
\hline $\begin{array}{l}\text { Carboxylate-coated magnetic } \\
\text { beads (hydrophilic) }\end{array}$ & Cytiva & $\begin{array}{l}\text { Cat\# } \\
45152105050250\end{array}$ \\
\hline Monensin & $A B C R$ & Cat\# AB349208 \\
\hline Bafilomycin & $A B C R$ & Cat\# AB355587 \\
\hline Rapamycin & $A B C R$ & Cat\# AB352180 \\
\hline
\end{tabular}




\begin{tabular}{|c|c|c|}
\hline TTFA & ABCR & Cat\# AB104115 \\
\hline 2-Deoxy-D-glucose & ABCR & Cat\# AB173119 \\
\hline 5/6-TAMRA-azide-biotin & Jena Bioscience & Cat\# CLK-1048-5 \\
\hline Fetal bovine serum & Thermo Fisher Scientific & Cat\# A3840001 \\
\hline Ethanol $(\mathrm{EtOH})$ & Merck & Cat\# 34852 \\
\hline Chloracetamide (CAA) & Sigma-Aldrich & Cat\# C0267-100g \\
\hline pro-N6pA probe & I & $\begin{array}{l}\text { (Kielkowski et al, } \\
\text { 2020b) }\end{array}$ \\
\hline GlcNAz probe & I & (Li et al, 2016) \\
\hline \multicolumn{3}{|l|}{ Software } \\
\hline MaxQuant & Cox et al., 2014 & $\begin{array}{l}\text { https://www.maxquant. } \\
\text { org/download_asset/m } \\
\text { axquant/latest }\end{array}$ \\
\hline Perseus & Tyanova et al., 2016 & $\begin{array}{l}\text { https://maxquant.net/d } \\
\text { ownload_asset/perseu } \\
\text { s/latest }\end{array}$ \\
\hline Origin & $\mathrm{N} / \mathrm{A}$ & $\begin{array}{l}\text { https://www.originlab.c } \\
\text { om/ }\end{array}$ \\
\hline \multicolumn{3}{|l|}{ Other } \\
\hline $\begin{array}{l}\text { Pierce } \circledast \text { BCA Protein Assay } \\
\text { Kit }\end{array}$ & Thermo Fisher Scientific & Cat\# 23225 \\
\hline $\begin{array}{l}\text { Orbitrap Eclipse Tribrid Mass } \\
\text { Spectrometer }\end{array}$ & Thermo Fisher Scientific & $\mathrm{N} / \mathrm{A}$ \\
\hline FAIMS Pro Duo Interface & Thermo Fisher Scientific & $\mathrm{N} / \mathrm{A}$ \\
\hline $\begin{array}{l}\text { PicoTip }{ }^{\mathrm{TM}} \text { Emitter, Silica } \\
\text { Tip }^{\mathrm{TM}}\end{array}$ & New Objectives & FS360-75-8-N-20-C15 \\
\hline ReproSil-Pur 120 C18-AQ & Dr. MaischGmbH & Cat\# R119.aq.0001 \\
\hline $\begin{array}{l}\text { PEPMAP100 C18 5UM } \\
0.3 \times 5 M M\end{array}$ & Thermo Fisher Scientific & Cat\# 160454 \\
\hline
\end{tabular}

\section{Methods and Protocols}

\section{Culturing of HeLa and SH-SY5Y cells}

HeLa (RRID: CVCL_0030) and SH-SY5Y (RRID: CVCL_0019) cells were cultured in Dulbeccos Modified Eagles Medium - high glucose (DMEM) supplemented with 10\% fetal calf serum (FCS) and $2 \mathrm{mM} \mathrm{L-alanyl-glutamine} \mathrm{at} 37^{\circ} \mathrm{C}$ and $5 \% \mathrm{CO}_{2}$ atmosphere.

\section{Probe and inhibitor treatment}

In each $10 \mathrm{~cm}$ dish 2.5 million HeLa or SH-SY5Y cells were seeded in $10 \mathrm{~mL}$ media. Cells were either treated with $10 \mu \mathrm{L}$ probe (100 mM stock pro-N6pA or $200 \mathrm{mM}$ stock GlcNAz) or with $10 \mu \mathrm{L}$ DMSO as a control. In case the cells were additionally treated with an inhibitor, the final concentrations were as follows: $100 \mathrm{nM}$ rapamycin, $100 \mathrm{nM}$ bafilomycin, $2 \mu \mathrm{M}$ monensin, $100 \mu \mathrm{M}$ TTFA and $4 \mu \mathrm{M}$ 2-Deoxy-D-glucose. For the monensin concentration dependency 
experiments the final monensin concentrations were $2 \mathrm{nM}, 20 \mathrm{nM}, 200 \mathrm{nM}, 1 \mu \mathrm{M}$ and $2 \mu \mathrm{M}$. After addition of probe and inhibitor, the cells were incubated $16 \mathrm{~h}$ at $37^{\circ} \mathrm{C}$ before harvesting. For this, the cells were washed twice with $2 \mathrm{~mL}$ DPBS, scrapped into $1 \mathrm{~mL}$ DPBS and pelleted at $260 \times \mathrm{g}, 4^{\circ} \mathrm{C}$.

\section{Cell lysis}

Cells were lysed with $500 \mu \mathrm{L}$ lysis buffer $(20 \mathrm{mM}$ Hepes, $\mathrm{pH} 7.5,1 \%(\mathrm{v} / \mathrm{v}) \mathrm{NP} 40,0.2 \%(\mathrm{w} / \mathrm{v})$ SDS) and sonicated for $10 \mathrm{~s}$ at $20 \%$ intensity with a rod sonicator. Lysate was clarified with $12,000 \mathrm{x} \mathrm{g}$ at $4{ }^{\circ} \mathrm{C}$ for $10 \mathrm{~min}$ and the protein concentration was determined by BCA. For optimization of different lysis buffers, following compositions were used: Lysis buffer 1 (8 M urea in $100 \mathrm{mM}$ Tris/HCl pH 8.5) Lysis buffer 2 (1\% NP-40 in PBS), Lysis buffer 3 (1\% NP-40, $0.2 \%$ SDS in PBS), Lysis buffer 4 (0.5\% Triton in PBS), Lysis buffer 5 (0.5\% Triton, $0.2 \%$ SDS in PBS), Lysis buffer 6 (1\% NP-40 in $20 \mathrm{mM}$ Hepes pH 7.5), Lysis buffer 7 (0.5\% Triton, 0.2\% SDS in $20 \mathrm{mM}$ Hepes pH 7.5), Lysis buffer 8 (0.5\% Triton in $20 \mathrm{mM}$ Hepes pH 7.5).

\section{Measurement of protein concentrations}

In order to measure the protein concentrations of the lysates, bicinchoninic acid assay was performed. First, bovine serum albumin (BSA) standards with concentrations of 12.5, 25, 50, 100,200 and $400 \mu \mathrm{g} / \mathrm{mL}$ were prepared and samples as well as controls were diluted 40 times to a total volume of $200 \mu \mathrm{L}$. To measure standards, samples and controls in triplicates, $50 \mu \mathrm{L}$ of each was added to three wells of a transparent 96-well plate with flat bottom. Afterwards, $100 \mu \mathrm{L}$ working reagent ( $2 \mu \mathrm{L} \mathrm{R} 2$ and $98 \mu \mathrm{L} \mathrm{R} 1)$ was added to each well by a multistepper and the plate was incubated $15 \mathrm{~min}$ at $60^{\circ} \mathrm{C}$. Then, the absorbance at $620 \mathrm{~nm}$ was measured by Tecan and the protein concentrations were calculated.

\section{SP2E workflow large scale}

$400 \mu \mathrm{g}$ protein of probe treated and control lysates were diluted with lysis buffer $(20 \mathrm{mM}$ Hepes, $\mathrm{pH} 7.5,1 \%(\mathrm{v} / \mathrm{v}) \mathrm{NP} 40,0.2 \%(\mathrm{w} / \mathrm{v}) \mathrm{SDS}$ ) to $200 \mu \mathrm{L}$ reaction volume. To each replicate, $2 \mu \mathrm{L}$ biotin-PEG-N ${ }_{3}$ (10 mM in DMSO), $2 \mu \mathrm{L}$ TCEP (100 mM in water) and $0.25 \mu \mathrm{L}$ TBTA (83.5 mM in DMSO) were added. Samples were gently vortexed, click reaction was initiated by the addition of $4 \mu \mathrm{L} \mathrm{CuSO}_{4}(50 \mathrm{mM}$ in water) and incubated for $1.5 \mathrm{~h}$ (rt, $600 \mathrm{rpm}$ ). Subsequently, $200 \mu \mathrm{L}$ of $8 \mathrm{M}$ urea was added to each replicate. $100 \mu \mathrm{L}$ of mixed hydrophobic and hydrophilic carboxylate-coated magnetic beads (1:1) were washed thrice with $500 \mu \mathrm{L}$ water. Click reaction mixture was directly transferred onto the equilibrated carboxylate-coated magnetic beads, resuspended and $600 \mu \mathrm{L}$ ethanol was added. After resuspending the beads via vortexing, suspension was incubated for $5 \mathrm{~min}$ at $\mathrm{rt}$ and $950 \mathrm{rpm}$. The beads were washed thrice with $500 \mu \mathrm{L}$ of $80 \%$ ethanol in water and the proteins were separately eluted by the 
addition of $0.5 \mathrm{~mL}$ of $0.2 \%$ SDS in PBS. For this, the beads were resuspended, incubated for $5 \mathrm{~min}$ at $950 \mathrm{rpm}$, rt and the supernatant was directly transferred onto $50 \mu \mathrm{L}$ equilibrated streptavidin-coated magnetic beads (3 times pre-washed with $500 \mu \mathrm{L} 0.2 \%$ SDS in PBS). The procedure was repeated once, the supernatants were combined and incubated for $1 \mathrm{~h}, \mathrm{rt}$ and $950 \mathrm{rpm}$ for biotin/streptavidin binding. The streptavidin-coated magnetic bead mixture was washed thrice with $500 \mu \mathrm{L} 0.1 \%$ NP40 in PBS, twice with $500 \mu \mathrm{L} 6 \mathrm{M}$ urea and twice with $500 \mu \mathrm{L}$ water. Washed bead mixtures were resuspended in $80 \mu \mathrm{L} 125 \mathrm{mM}$ ABC buffer and proteins were reduced and alkylated by the addition of $10 \mu \mathrm{L} 100 \mathrm{mM}$ TCEP and $10 \mu \mathrm{L}$ $400 \mathrm{mM}$ chloracetamide and $5 \mathrm{~min}$ incubation at $95^{\circ} \mathrm{C}$. Proteins were digested overnight at $37^{\circ} \mathrm{C}$ with $1.5 \mu \mathrm{L}$ sequencing grade trypsin $(0.5 \mathrm{mg} / \mathrm{mL})$. The following day, the beads were washed thrice with $100 \mu \mathrm{L} 100 \mathrm{mM} \mathrm{ABC}$ buffer and the supernatants were combined and acidified with $2 \mu \mathrm{L}$ formic acid. Peptides were desalted using $50 \mathrm{mg}$ SepPak C18 cartridges on a vacuum manifold. The columns were equilibrated with $1 \mathrm{~mL}$ acetonitrile, $1 \mathrm{~mL}$ elution buffer ( $80 \%$ acetonitrile with $0.5 \%$ formic acid in water) and $3 \mathrm{~mL}$ wash buffer $(0.5 \%$ formic acid in water). Subsequently, the samples were loaded on the cartridges and washed with $3 \mathrm{~mL}$ wash buffer. The peptides were eluted two times with $250 \mu \mathrm{L}$ elution buffer and vacuum dried with a SpeedVac at $35^{\circ} \mathrm{C}$. Finally, dried peptides were reconstituted in $30 \mu \mathrm{L} 1 \%$ formic acid in water by vortexing and sonication (15 $\mathrm{min}$ ) and transferred to a MS vial.

During the optimization process, we performed this workflow with the following changes. The first attempts were performed without a separate elution step of the proteins from the carboxylated beads. In these attempts one was performed without the addition of $8 \mathrm{M}$ urea after the click reaction. Furthermore, once the reduction and alkylation was performed prior to the click reaction. In addition, TEAB was used instead of $A B C$ buffer for the digest. Another attempt was to reduce the starting protein amount from $400 \mu \mathrm{g}$ to $100 \mu \mathrm{g}$.

\section{SP2E workflow small scale}

$100 \mu \mathrm{g}$ protein of probe treated and control lysates were diluted with lysis buffer $(20 \mathrm{mM}$ Hepes, $\mathrm{pH} 7.5,1 \%(\mathrm{v} / \mathrm{v}) \mathrm{NP} 40,0.2 \%(\mathrm{w} / \mathrm{v}) \mathrm{SDS})$ to $19 \mu \mathrm{L}$ reaction volume in a 96-well plate. To each replicate, $0.2 \mu \mathrm{L}$ biotin-PEG- $\mathrm{N}_{3}$ (10 mM in DMSO), $0.2 \mu \mathrm{L}$ TCEP (100 mM in water) and $0.125 \mu \mathrm{L}$ TBTA (16.7 mM in DMSO) were added. Samples were gently vortexed, click reaction was initiated by the addition of $0.4 \mu \mathrm{L} \mathrm{CuSO}_{4}(50 \mathrm{mM}$ in water) and incubated for $1.5 \mathrm{~h}$ (rt, $600 \mathrm{rpm}$ ). Subsequently, $60 \mu \mathrm{L}$ of $8 \mathrm{M}$ urea was added to each replicate. $100 \mu \mathrm{L}$ of mixed hydrophobic and hydrophilic carboxylate-coated magnetic beads (1:1) were washed thrice with $100 \mu \mathrm{L}$ water. Click reaction mixture was directly transferred onto the equilibrated carboxylatecoated magnetic beads, resuspended and $100 \mu \mathrm{L}$ of absolute ethanol was added. After resuspending the beads via vortexing, suspension was incubated for $5 \mathrm{~min}$ at rt and $950 \mathrm{rpm}$. The beads were washed thrice with $150 \mu \mathrm{L}$ of $80 \%$ ethanol in water and once with $150 \mu \mathrm{L}$ 
acetonitrile (LC-MS). Proteins were separately eluted by the addition of $60 \mu \mathrm{L}$ of $0.2 \%$ SDS in PBS. For this, the beads were resuspended, incubated for $5 \mathrm{~min}$ at $40{ }^{\circ} \mathrm{C}$ and $950 \mathrm{rpm}$ and the supernatant was directly transferred onto $50 \mu \mathrm{L}$ equilibrated streptavidin-coated magnetic beads ( 3 times pre-washed with $100 \mu \mathrm{L} 0.2 \%$ SDS in PBS). The procedure was repeated twice, the supernatants were combined and incubated for $1 \mathrm{~h}$ at $\mathrm{rt}$ and $800 \mathrm{rpm}$ for biotin/streptavidin binding. The streptavidin-coated magnetic bead mixture was washed thrice with $150 \mu \mathrm{L} 0.1 \% \mathrm{NP} 40$ in PBS, twice with $150 \mu \mathrm{L} 6 \mathrm{M}$ urea and twice with $150 \mu \mathrm{L}$ water. For each washing step, the beads were incubated $1 \mathrm{~min}$ at $\mathrm{rt}$ and $800 \mathrm{rpm}$. Washed bead mixtures were resuspended in $50 \mu \mathrm{L} 50 \mathrm{mM}$ TEAB and proteins were digested overnight at $37^{\circ} \mathrm{C}$ by addition of $1.5 \mu \mathrm{L}$ sequencing grade trypsin $(0.5 \mathrm{mg} / \mathrm{mL})$. The following day, the beads were washed twice with $20 \mu \mathrm{L} 50 \mathrm{mM}$ TEAB buffer and twice with $20 \mu \mathrm{L} 0.5 \%$ FA and the wash fractions were collected and combined. For each washing step, the beads were incubated $5 \mathrm{~min}$ at $40^{\circ} \mathrm{C}$ and $600 \mathrm{rpm}$. The combined washed fractions were acidified by addition of $0.9 \mu \mathrm{L}$ formic acid (FA) and transferred to an MS-vial.

\section{SPAAC protocol}

$400 \mu \mathrm{g}$ protein of probe treated and control lysates were diluted with lysis buffer $(20 \mathrm{mM}$ Hepes, $\mathrm{pH} 7.5,1 \%(\mathrm{v} / \mathrm{v}) \mathrm{NP} 40,0.2 \%$ (w/v) SDS) to $200 \mu \mathrm{L}$ reaction volume. To each replicate, $3 \mu \mathrm{L}$ of $1 \mathrm{M}$ IAA in water was added and incubated for $30 \mathrm{~min}$ at $750 \mathrm{rpm}, 25^{\circ} \mathrm{C}$. Next, $2 \mu \mathrm{L}$ of $2 \mathrm{mM}$ DBCO-PEG-N3 reagent was added to initiate SPAAC reaction. The reaction mixtures were incubated at $25^{\circ} \mathrm{C}, 750 \mathrm{rpm}$ for $30 \mathrm{~min}$. The samples were proceeded further in the same way as for CuAAC.

\section{MS-measurement}

MS measurements were performed on an Orbitrap Eclipse Tribrid Mass Spectrometer (Thermo Fisher Scientific) coupled to an UltiMate 3000 Nano-HPLC (Thermo Fisher Scientific) via an EASY-Spray source (Thermo Fisher Scientific) and FAIMS interface (Thermo Fisher Scientific). First, peptides were loaded on an Acclaim PepMap $100 \mu$-precolumn cartridge (5 $\mu \mathrm{m}, 100 \AA, 300 \mu \mathrm{m}$ ID $\times 5$ mm, Thermo Fisher Scientific). Then, peptides were separated at $40{ }^{\circ} \mathrm{C}$ on a PicoTip emitter (noncoated, $15 \mathrm{~cm}, 75 \mu \mathrm{m}$ ID, $8 \mu \mathrm{m}$ tip, New Objective) that was in house packed with Reprosil-Pur $120 \mathrm{C} 18-\mathrm{AQ}$ material (1.9 $\mu \mathrm{m}, 150 \AA$, Dr. A. Maisch GmbH). The long gradient was run from $4-35.2 \%$ acetonitrile supplemented with $0.1 \%$ formic acid during a $150 \mathrm{~min}$ method $(0-5 \min 4 \%, 5-6 \min$ to $7 \%, 7-105 \min$ to $24.8 \%, 105-126$ min to $35.2 \%, 126-140 \mathrm{~min} 80 \%, 140-150 \mathrm{~min} 4 \%$ ) at a flow rate of $300 \mathrm{~nL} / \mathrm{min}$. The short gradient was run from $4-35.2 \%$ acetonitrile supplemented with $0.1 \%$ formic acid during a 60 min method (0-5 $\min 4 \%, 5-6 \min$ to $7 \%, 7-36 \min$ to $24.8 \%, 37-41 \min$ to $35.2 \%, 42-46 \min 80 \%, 47-60$ $\min 4 \%$ ) at a flow rate of $300 \mathrm{~nL} / \mathrm{min}$. FAIMS was performed with two alternating $\mathrm{CVs}$ including 
$-50 \mathrm{~V}$ and $-70 \mathrm{~V}$. For measurements of chemical-proteomics samples, the Orbitrap Eclipse Tribrid Mass Spectrometer was operated in dd-MS ${ }^{2}$ mode with following settings: Polarity: positive; $M S^{1}$ resolution: $240 \mathrm{k}$; $M S^{1}$ AGC target: standard; $M S^{1}$ maximum injection time: 50 ms; $M^{1}{ }^{1}$ scan range: $\mathrm{m} / \mathrm{z} 375-1500 ; \mathrm{MS}^{2}$ ion trap scan rate: rapid; $\mathrm{MS}^{2} \mathrm{AGC}$ target: standard; $\mathrm{MS}^{2}$ maximum injection time: $35 \mathrm{~ms}$; $\mathrm{MS}^{2}$ cycle time: $1.7 \mathrm{~s}$; $\mathrm{MS}^{2}$ isolation window: $\mathrm{m} / \mathrm{z} 1.2$; HCD stepped normalised collision energy: $30 \%$; intensity threshold: $1.0 \mathrm{e} 4$ counts; included charge states: 2-6; dynamic exclusion: $60 \mathrm{~s}$.

\section{Quantification and statistical analysis}

MS raw files were analysed using MaxQuant software 2.0.1.0 with the Andromeda search engine. Searches were performed against the Uniprot database for Homo sapiens (taxon identifier: 9606, March 2020). At least two unique peptides were required for protein identification. False discovery rate determination was carried out using a decoy database and thresholds were set to $1 \%$ FDR both at peptide-spectrum match and at protein levels. LFQ quantification was used as described for each sample. For calculation of the large scale samples, carbamidomethylation was set as a fixed modification and methionine oxidation as well as $\mathrm{N}$-terminal acetylation as a variable modification. In contrast, the small scale samples of the 96-well plate were calculated without carbamidomethylation as a fixed modification.

Statistical analysis of the MaxQuant result table proteinGroups.txt was done with Perseus 1.6.10.43. First, LFQ intensities were $\log _{2}$-transformed. Afterwards, potential contaminants as well as reverse peptides were removed. Then, the rows were divided into two groups - DMSO (control) and probe treated sample (sample). Subsequently, the groups were filtered for at least three valid values out of four rows in at least one group and the missing values were replaced from normal distribution. The $-\log _{10}(p$-values) were obtained by a two-sided one sample Student's t-test over replicates with the initial significance level of $p=0.05$ adjustment by the multiple testing correction method of Benjamini and Hochberg (FDR $=0.05$ ) using the volcano plot function.

\section{Western blot analysis}

For each Western blot analysis, $20 \mu \mathrm{g}$ cell lysate was used. In order to denature proteins, $4 \mu \mathrm{L}$ $5 \times$ Laemmli buffer (10\% (w/v) SDS, 50\% (v/v) glycerol, 25\% (v/v) $\beta$-mercaptoethanol, 0.5\% (w/v) bromphenol blue, $315 \mathrm{mM}$ Tris/ $\mathrm{HCl}, \mathrm{pH} 6.8$ ) was added to $16 \mu \mathrm{L}$ lysate solution and the samples were boiled $5 \mathrm{~min}$ at $95^{\circ} \mathrm{C}$. Afterwards, $20 \mu \mathrm{L}$ of each sample was loaded onto a 7.5 , 10 or $12.5 \%$ SDS gel and proteins were separated according to their size by SDS-PAGE. Then, the separated proteins were transferred onto a membrane using a blotting sandwich moistened by blotting buffer (48 mM Tris, $39 \mathrm{mM}$ glycine, $0.0375 \%$ (m/v) SDS, 20\% (v/v) methanol), which 
was composed of one extra thick blot paper, the PVDF transfer membrane, the SDS-PAGE gel and again one extra thick blot paper. Before the protein transfer was carried out 45 min at $25 \mathrm{~V}$ using a Semi Dry Blotter (Bio-Rad), the transfer membrane was pre-incubated 5 min in methanol. In order to block non-specific binding sites, the membrane was incubated 60 min in blocking solution ( $0.5 \mathrm{~g}$ milk powder in $10 \mathrm{~mL}$ PBST (PBS $+0.5 \%$ Tween)). Subsequently, $10 \mu \mathrm{L}$ primary antibody with specificity for the protein of interest was added and the mixture was incubated $1 \mathrm{~h}$ at room temperature. The membrane was washed 3 times for 10 min with PBST before $1 \mu \mathrm{L}$ of the secondary HRP antibody in $10 \mathrm{~mL}$ blocking solution was added. After $1 \mathrm{~h}$ of incubation at room temperature, the membrane was washed again 3 times for 10 min with PBST. Then, $400 \mu \mathrm{L}$ ECL Substrate and $400 \mu \mathrm{L}$ peroxide solution were mixed and added to the membrane to stain the Western blot. Finally, images of the Western blot were taken by developing machine Amersham Imager 680 (GE Healthcare).

\section{Trifunctional linker enrichment}

$400 \mu \mathrm{g}$ protein of probe treated and control lysates were diluted with lysis buffer $(20 \mathrm{mM}$ Hepes, $\mathrm{pH} 7.5,1 \%(\mathrm{v} / \mathrm{v}) \mathrm{NP} 40,0.2 \%$ (w/v) SDS) to $200 \mu \mathrm{L}$ reaction volume. To each replicate, $2 \mu \mathrm{L}$ 5/6-TAMRA-azide-biotin (10 mM in DMSO), $2 \mu \mathrm{L}$ TCEP (100 mM in water) and $0.25 \mu \mathrm{L}$ TBTA (83.5 mM in DMSO) were added. Samples were gently vortexed, click reaction was initiated by the addition of $4 \mu \mathrm{L} \mathrm{CuSO}_{4}$ ( $50 \mathrm{mM}$ in water) and incubated for $1.5 \mathrm{~h} \mathrm{(rt,} 600 \mathrm{rpm}$ ). The clean-up of the click reaction mixture on the carboxylate magnetic beads as well as the subsequent enrichment on the streptavidin magnetic beads was performed as described in the above section of the SP2E large scale protocol. The enriched proteins were eluted from the beads by addition of $50 \mu \mathrm{L} 1 \mathrm{x}$ Laemmli buffer and 5 min incubation at $95^{\circ} \mathrm{C}$. Finally, $20 \mu \mathrm{L}$ of the eluate were loaded on a SDS-gel and the western blot was performed as described in the above section.

\section{Data Availability}

Proteomics data are freely available at ProteomeXchange Consortium via PRIDE partner repository with the dataset identifier PXD030960.

\section{Acknowledgements}

This research project was supported by Liebig fellowship from $\mathrm{VCl}$ to $\mathrm{PK}$ and $\mathrm{TB}$, LMUexcellence Junior Fund to PK and SFB1309 by DFG.

\section{Author contribution}

PK designed the method; AW, AT and DB performed the experiments and optimization of the method; TB carried out the AMPylation study; A H.-R. provided the GlcNAz probe and 
bioRxiv preprint doi: https://doi org/101101/2022.01.24 477214; this version posted January 25,2022 . The copyright holder for this preprint (which was not certified by peer review) is the author/funder, who has granted bioRxiv a license to display the preprint in perpetuity. It is made available under aCC-BY-NC 4.0 International license.

experience in O-GlcNAcylation. TB and PK overviewed the study and analyzed the data; TB and PK wrote the manuscript with input from all authors.

\section{Conflict of interest}

The authors declare that they have no conflict of interest.

\section{References}

Aebersold R, Agar JN, Amster IJ, Baker MS, Bertozzi CR, Boja ES, Costello CE, Cravatt BF, Fenselau C, Garcia BA, et al (2018) How many human proteoforms are there? Nature chemical biology 14: 206-214

Agard NJ, Prescher JA \& Bertozzi CR (2004) A Strain-Promoted [3 + 2] Azide-Alkyne Cycloaddition for Covalent Modification of Biomolecules in Living Systems. Journal of the American Chemical Society 126: $15046-15047$

Becker T, Cappel C, Matteo FD, Sonsalla G, Kaminska E, Spada F, Cappello S, Damme M \& Kielkowski $P$ (2021) AMPylation profiling during neuronal differentiation reveals extensive variation on lysosomal proteins. Iscience 24: 103521

Brüning F, Noya SB, Bange T, Koutsouli S, Rudolph JD, Tyagarajan SK, Cox J, Mann M, Brown SA \& Robles MS (2019) Sleep-wake cycles drive daily dynamics of synaptic phosphorylation. Science 366: eaav3617

Cox J, Hein MY, Luber CA, Paron I, Nagaraj N \& Mann M (2014) Accurate proteome-wide label-free quantification by delayed normalization and maximal peptide ratio extraction, termed MaxLFQ. Molecular \& Cellular Proteomics 13: 2513-2526

Cox J \& Mann M (2008) MaxQuant enables high peptide identification rates, individualized p.p.b.range mass accuracies and proteome-wide protein quantification. Nature Biotechnology 26: 13671372

Grammel M, Luong P, Orth K \& Hang HC (2011) A Chemical Reporter for Protein AMPylation. Journal of the American Chemical Society 133: 17103-17105

Hoch NC \& Polo LM (2020) ADP-ribosylation: from molecular mechanisms to human disease. Genet Mol Biol 43: e20190075

Hughes CS, Foehr S, Garfield DA, Furlong EE, Steinmetz LM \& Krijgsveld J (2014) Ultrasensitive proteome analysis using paramagnetic bead technology. Mol Syst Biol 10: 1-10

Hughes CS, Moggridge S, Müller T, Sorensen PH, Morin GB \& Krijgsveld J (2019) Single-pot, solidphase-enhanced sample preparation for proteomics experiments. Nat Protoc 14: 68-85

Kallemeijn WW, Lanyon-Hogg T, Panyain N, Grocin AG, Ciepla P, Morales-Sanfrutos J \& Tate EW (2021) Proteome-wide analysis of protein lipidation using chemical probes: in-gel fluorescence visualization, identification and quantification of $\mathrm{N}$-myristoylation, $\mathrm{N}$ - and S-acylation, $\mathrm{O}-$ cholesterylation, S-farnesylation and S-geranylgeranylation. Nat Protoc 16: 5083-5122

Kam T-I, Mao X, Park H, Chou S-C, Karuppagounder SS, Umanah G, Yun S, Brahmachari S, Panicker N, Chen R, et al (2018) Poly(ADP-ribose) drives pathologic $\alpha$-synuclein neurodegeneration in Parkinson's disease. Science 362: eaat8407 
bioRxiv preprint doi: https://doi org/101101/2022.01.24 477214: this version posted January 25,2022 . The copyright holder for this preprint (which was not certified by peer review) is the author/funder, who has granted bioRxiv a license to display the preprint in perpetuity. It is made available under aCC-BY-NC 4.0 International license.

Kielkowski P, Buchsbaum IY, Becker T, Bach K, Cappello S \& Sieber SA (2020a) A Pronucleotide Probe for Live-Cell Imaging of Protein AMPylation. Chembiochem

Kielkowski P, Buchsbaum IY, Kirsch VC, Bach NC, Drukker M, Cappello S \& Sieber SA (2020b) FICD activity and AMPylation remodelling modulate human neurogenesis. Nat Commun 11: 517

Kliza KW, Liu Q, Roosenboom LWM, Jansen PWTC, Filippov DV \& Vermeulen M (2021) Reading ADP-ribosylation signaling using chemical biology and interaction proteomics. Mol Cell 81: 45524567.e8

Klont F, Kwiatkowski M, Faiz A, Bosch T van den, Pouwels SD, Dekker FJ, Hacken NHT ten, Horvatovich P \& Bischoff R (2021) Adsorptive Microtiter Plates As Solid Supports in Affinity Purification Workflows. J Proteome Res 20: 5218-5221

Laughlin ST \& Bertozzi CR (2007) Metabolic labeling of glycans with azido sugars and subsequent glycan-profiling and visualization via Staudinger ligation. Nat Protoc 2: 2930-2944

Leeman DS, Hebestreit K, Ruetz T, Webb AE, McKay A, Pollina EA, Dulken BW, Zhao X, Yeo RW, Ho TT, et al (2018) Lysosome activation clears aggregates and enhances quiescent neural stem cell activation during aging. Science 359: 1277-1283

Li J, Wang J, Wen L, Zhu H, Li S, Huang K, Jiang K, Li X, Ma C, Qu J, et al (2016) An OGA-Resistant Probe Allows Specific Visualization and Accurate Identification of $O$-GlcNAc-Modified Proteins in Cells. Acs Chem Biol 11: 3002-3006

Long JM \& Holtzman DM (2019) Alzheimer Disease: An Update on Pathobiology and Treatment Strategies. Cell

Makowski MM, Gräwe C, Foster BM, Nguyen NV, Bartke T \& Vermeulen M (2018) Global profiling of protein-DNA and protein-nucleosome binding affinities using quantitative mass spectrometry. Nat Commun 9: 1653

Mansfield SG \& Gordon-Weeks PR (1991) Dynamic post-translational modification of tubulin in rat cerebral cortical neurons extending neurites in culture: Effects of taxol. J Neurocytol 20: 654-666

Martin BR, Wang C, Adibekian A, Tully SE \& Cravatt BF (2011) Global profiling of dynamic protein palmitoylation. Nature methods 9: 84-9

Mollenhauer HH, Morré DJ \& Rowe LD (1990) Alteration of intracellular traffic by monensin; mechanism, specificity and relationship to toxicity. Biochimica Et Biophysica Acta Bba-Rev Biomembr 1031: 225-246

Müller T, Kalxdorf M, Longuespée R, Kazdal DN, Stenzinger A \& Krijgsveld J (2020) Automated sample preparation with SP3 for low-input clinical proteomics. Mol Syst Biol 16: e9111

Parker CG \& Pratt MR (2020) Click Chemistry in Proteomic Investigations. Cell

Pedowitz NJ \& Pratt MR (2021) Design and synthesis of metabolic chemical reporters for the visualization and identification of glycoproteins. Rsc Chem Biology 2: 306-321

Pentelute B, Zhang C, Dai P, Vinogradov A \& Gates Z (2018) Site-Selective Cysteine-Cyclooctyne Conjugation. Angewandte Chemie (International ed in English)

Raught B, Gingras A-C \& Sonenberg N (2001) The target of rapamycin (TOR) proteins. Proceedings of the National Academy of Sciences of the United States of America: 7037-7044 
bioRxiv preprint doi: https://doi.org/10.1101/2022.0124 477214; this version posted January 25,2022 . The copyright holder for this preprint (which was not certified by peer review) is the author/funder, who has granted bioRxiv a license to display the preprint in perpetuity. It is made available under aCC-BY-NC 4.0 International license.

Rogowski K, Dijk J van, Magiera MM, Bosc C, Deloulme J-C, Bosson A, Peris L, Gold ND, Lacroix B, Grau MB, et al (2010) A Family of Protein-Deglutamylating Enzymes Associated with Neurodegeneration. Cell 143: 564-578

Sanyal A, Dutta S, Camara A, Chandran A, Koller A, Watson BG, Sengupta R, Ysselstein D, Montenegro P, Cannon J, et al (2019) Alpha-Synuclein Is a Target of Fic-Mediated Adenylylation/AMPylation: Possible Implications for Parkinson's Disease. J Mol Biol

Sieber SA, Cappello S \& Kielkowski P (2020) From Young to Old: AMPylation Hits the Brain. Cell Chem Biol

Sielaff M, Kuharev J, Bohn T, Hahlbrock J, Bopp T, Tenzer S \& Distler U (2017) Evaluation of FASP, SP3, and iST Protocols for Proteomic Sample Preparation in the Low Microgram Range. $J$ Proteome Res 16: 4060-4072

Sinha A \& Mann M (2020) A beginner's guide to mass spectrometry-based proteomics. Biochem

Smith LM, Agar JN, Chamot-Rooke J, Danis PO, Ge Y, Loo JA, Paša-Tolić L, Tsybin YO, Kelleher NL \& Proteomics TC for T-D (2021) The Human Proteoform Project: Defining the human proteome. Sci Adv 7: eabk0734

Smith LM, Thomas PM, Shortreed MR, Schaffer LV, Fellers RT, LeDuc RD, Tucholski T, Ge Y, Agar JN, Anderson LC, et al (2019) A five-level classification system for proteoform identifications. Nature Methods: 1-2

Truttmann MC, Pincus D \& Ploegh HL (2018) Chaperone AMPylation modulates aggregation and toxicity of neurodegenerative disease-associated polypeptides. Proceedings of the National Academy of Sciences: 201801989

Truttmann MC, Zheng X, Hanke L, Damon JR, Grootveld M, Krakowiak J, Pincus D \& Ploegh HL (2017) Unrestrained AMPylation targets cytosolic chaperones and activates the heat shock response. Proceedings of the National Academy of Sciences 114: E152-E160

Tyanova S, Temu T, Sinitcyn P, Carlson A, Hein MY, Geiger T, Mann M \& Cox J (2016) The Perseus computational platform for comprehensive analysis of (prote)omics data. Nature methods 13: 73140

Wiśniewski JR, Zougman A, Nagaraj N \& Mann M (2009) Universal sample preparation method for proteome analysis. Nat Methods 6: 359-362

Wright MH, Clough B, Rackham MD, Rangachari K, Brannigan JA, Grainger M, Moss DK, Bottrill AR, Heal WP, Broncel M, et al (2014) Validation of N-myristoyltransferase as an antimalarial drug target using an integrated chemical biology approach. Nature Chemistry 6: 112-121

Wulff-Fuentes E, Berendt RR, Massman L, Danner L, Malard F, Vora J, Kahsay R \& Stichelen SO-V (2021) The human O-GlcNAcome database and meta-analysis. Sci Data 8: 25

Yan T, Desai HS, Boatner LM, Yen SL, Cao J, Palafox MF, Jami-Alahmadi Y \& Backus K (2021) SP3FAIMS chemoproteomics for high coverage profiling of the human cysteinome. ChemBioChem

Yang X \& Qian K (2017) Protein O-GlcNAcylation: emerging mechanisms and functions. Nat Rev Mol Cell Bio 18: 452-465

Yang Y-Y, Ascano JM \& Hang HC (2010) Bioorthogonal Chemical Reporters for Monitoring Protein Acetylation. Journal of the American Chemical Society 132: 3640-1 
bioRxiv preprint doi: https://doi org/10.1101/2022 $0124.477214 \cdot$ this version posted January 25,2022 . The copyright holder for this preprint (which was not certified by peer review) is the author/funder, who has granted bioRxiv a license to display the preprint in perpetuity. It is made available under aCC-BY-NC 4.0 International license.

Yoshimori T, Yamamoto A, Moriyama Y, Futai M \& Tashiro Y (1991) Bafilomycin A1, a specific inhibitor of vacuolar-type $\mathrm{H}(+)$-ATPase, inhibits acidification and protein degradation in lysosomes of cultured cells. J Biol Chem 266: 17707-17712

Yu F, Teo GC, Kong AT, Haynes SE, Avtonomov DM, Geiszler DJ \& Nesvizhskii Al (2020) Identification of modified peptides using localization-aware open search. Nat Commun 11: 4065

Zecha J, Satpathy S, Kanashova T, Avanessian SC, Kane MH, Clauser KR, Mertins P, Carr SA \& Kuster B (2019) TMT Labeling for the Masses: A Robust and Cost-efficient, In-solution Labeling Approach* $^{*}$ [S. Mol Cell Proteomics 18: 1468-1478

Zhang J-G \& Fariss MW (2002) Thenoyltrifluoroacetone, a potent inhibitor of carboxylesterase activity. Biochem Pharmacol 63: 751-754

Zheng P, Obara CJ, Szczesna E, Nixon-Abell J, Mahalingan KK, Roll-Mecak A, Lippincott-Schwartz J \& Blackstone C (2021) ER proteins decipher the tubulin code to regulate organelle distribution. Nature: $1-7$ 